\title{
Comparación de tres métodos de extracción de ADN a partir de garrapatas duras (Acari: Ixodidae)
}

\section{Comparison of three DNA extraction methods from hard ticks (Acari: Ixodidae)}

\author{
Marco Guevara-Vega ; Melba Vertel-Morinson²; Luis Enrique Paternina ${ }^{3 *}$
}

Biólogo, Grupo Investigaciones Biomédicas. Universidad de Sucre, Sincelejo, Colombia, e-mail: marco.guevara.vega@gmail.com, (Dhttps://orcid.org/00000003-2332-0886

${ }^{2}$ Licenciada en Matemáticas y Física, M.Sc. Grupo Investigaciones Estadística y Modelamiento Matemático Aplicado a Calidad Educativa. Universidad de Sucre, Sincelejo, Colombia, e-mail: melba.vertel@unisucre.edu.co, Dhttps://orcid.org/0000-0002-3204-5145

${ }^{3}$ Biólogo, M.Sc. Dr. Sci. Grupo Investigaciones Biomédicas. Universidad de Sucre, Sincelejo, Colombia, Carrera 14 No. 16B - 32, e-mail: lepaterninat@gmail.com, (Dhttps://orcid.org/0000-0003-0522-2924

*autor de correspondencia: lepaterninat@gmail.com

Cómo citar: Guevara-Vega, M.; Vertel-Morinson, M.; Paternina, L.E. 2019. Comparación de tres métodos de extracción de ADN a partir de garrapatas duras (Acari: Ixodidae). Rev. U.D.C.A Act. \& Div. Cient. 22(1):e1208. https://doi.org/10.31910/rudca.v22.n1.2019.1208

Artículo de acceso abierto publicado por Revista U.D.C.A Actualidad \& Divulgación Científica bajo una licencia Creative Commons CC BY-NC 4.0

Recibido: Septiembre 4 de 2018

Aceptado: Abril 29 de 2019

\section{RESUMEN}

Las garrapatas son el grupo de ectoparásitos de mayor relevancia en la transmisión de patógenos a los animales domésticos y a humanos. La detección de estos agentes, normalmente, se realiza por métodos basados en PCR y, por ello, se requiere de la obtención de ácidos nucleicos, para la amplificación selectiva de dianas moleculares. El objetivo de la presente investigación fue comparar el desempeño de tres métodos de extracción de ADN, sales, columnas y tiocianato de guanidina, a partir de garrapatas, para estudios de detección de patógenos y sistemática molecular de garrapatas. Se realizaron comparaciones múltiples del desempeño de extracción sobre 30 muestras de garrapatas y se valoró la calidad del extracto de ADN, mediante la amplificación de un fragmento del gen mitocondrial 16S de garrapatas, con la utilización de la técnica de PCR. Además, se evaluó la presencia de patógenos de los géneros Rickettsia, Ehrlichia, Anaplasma y Babesia. El método con mayor desempeño en la extracción de ADN fue el basado en tiocianato de guanidina $(\mathrm{mdnR}=160 \mathrm{ng} / \mathrm{uL})$, seguido por columnas $(\mathrm{mdnR}=4,7 \mathrm{ng} / \mathrm{uL})$ y luego sales (mdnR=1,6ng/uL). Se presentaron diferencias estadísticas en el rendimiento de la extracción; no obstante, no existieron diferencias respecto al éxito de amplificación, mediante PCR, de acuerdo con el método de extracción ( $\mathrm{p}=0,1173)$. No se detectaron patógenos rickettsiales o piroplasmas en ninguno de los extractos de ADN de garrapatas evaluados. Considerando el costo/ beneficio de los métodos comparados, la utilización del método de sales puede facilitar la masificación de trabajos sobre la detección de patógenos que son transmitidos por garrapatas, en laboratorios de discreto presupuesto.

Palabras clave: agentes patógenos; PCR; sistemática molecular; ectoparásitos; vectores de enfermedades. (Mesh).

\section{ABSTRACT}

Ticks are the most important group of ectoparasites in the transmission of pathogens to domestic animals and humans. Detection of those pathogens is usually performed by PCR-based 
methods and therefore requires the extraction of nucleic acids for the selective amplification of molecular targets. The aim of the present investigation was to compare the performance of three DNA extraction methods (salts, columns and guanidine thiocyanate) from ticks for studies of pathogen detection and molecular systematics of ticks. DNA extraction performance was measured by multiple comparisons on 30 tick samples and assessment of quality of the DNA extract through PCR amplification of $16 \mathrm{~S}$ mitochondrial ticks gene. The presence of Rickettsia, Ehrlichia, Anaplasma and Babesia were also evaluated. The guanidine thiocyanate was the method with highest performance $(\mathrm{mdnR}=160 \mathrm{ng} / \mathrm{uL})$, then columns $(\mathrm{mdnR}=$ $4.7 \mathrm{ng} / \mathrm{uL})$ and finally salting out method $(\operatorname{mdnR}=1.6 \mathrm{ng} / \mathrm{uL})$. Although there were statistical differences of performance among DNA extraction protocols, there were no differences regarding the success of PCR amplification according to the extraction method $(p=0.1173)$. No rickettsial pathogens or piroplasms were detected in any of the DNA extracts evaluated. Considering the cost/benefit ratio of the three methods, the use of the salting out method can facilitate the massification of studies on tick-borne pathogen in low-budget laboratories.

Keywords: pathogens; PCR; molecular systematics; ectoparasites; disease vectors. (Mesh).

\section{INTRODUCCIÓN}

Las garrapatas son un grupo importante de artrópodos y de vectores, que se caracterizan por la transmisión de microorganismos patógenos, como Babesia, Hepatozoon, Borrelia, Rickettsia, Anaplasma y Ehrlichia (Boulanger et al. 2019; Jongejan et al. 2004) y, además, por su impacto en la salud humana y animal, a nivel mundial y su implicación socioeconómica (Cabezas-Cruz et al. 2018; Parola et al. 2001). Tradicionalmente, la identificación de garrapatas y sus agentes patógenos, se fundamentan en la amplificación por reacción en cadena de la polimerasa - PCR y su posterior secuenciación de ADN. Estos métodos requieren del aislamiento y la purificación exitosa del material genético total, para luego ser utilizado como plantilla en la amplificación selectiva de secuencias diana de garrapatas y microorganismos asociados a ellas (Parola et al. 2001).

En la extracción de ADN, a partir de garrapatas, existen numerosos protocolos reportados en la literatura, que van desde el uso de productos comercialmente disponibles, basados en columnas, hasta métodos tradicionales de laboratorio, como Fenol-Cloroformo y altas concentraciones salinas (Aljanabi \& Martínez, 1997; Halos et al. 2004; Ammazzalorso et al. 2015). Estos métodos de extracción de ADN han sido empleados en estudios taxonómicos y de sistemática de garrapatas, donde se requiere la amplificación de regiones mitocondriales 12S y 16S (Black \& Piesman, 1994; Nava et al. 2009), el gen ribosomal nuclear $18 \mathrm{~S}$ (Black et al. 1997) y las secuencias intergénicas, como ITS2 (Marrelli et al. 2007). También, han sido usados para la exploración de las fuentes alimenticias de garrapatas, donde se requiere la amplificación de regiones mitocondriales de vertebrados, a partir de la sangre ingerida por el ectoparásito (Pichon et al. 2003; Pichon et al. 2005). De la misma forma, para la detección de agentes patógenos transmitidos por garrapatas, como rickettsiales, borrelias y piroplasmas (Guedes et al. 2005; Barbieri et al. 2013; Nava et al. 2014; Campos-Calderón et al. 2016).

Independientemente del método de extracción de $\mathrm{ADN}$ seleccionado o utilizado con pequeñas modificaciones han demostrado ser útiles, en el estudio de aspectos taxonómicos, ecológicos y vectoriales de las garrapatas, aunque se desconoce si alguno de ellos es mejor que los demás, en consideración de las relaciones costo/beneficio y su potencial uso para el estudio de los patógenos transmitidos por garrapatas, en áreas de escasa cobertura científica y presupuestal.

En Colombia, existen registros de, al menos, 58 especies de garrapatas, la mayoría de ellas, se desconoce si tienen roles como vectores de enfermedades para los humanos (Rivera-Páez et al. 2017), lo que indica, que la información es escaza; sin embargo, algunas de ellas resaltan por su gran importancia: el complejo Amblyomma cajennense s.l., por su relevancia como vectores principales de la Fiebre Manchada de Las Montañas Rocosas (FMMR); Rhipicephalus microplus, como vector de Babesiosis y Anaplasmosis Bovina, que causa millonarias pérdidas en el sector productivo (Sonenshine et al. 2002) y Rhipicephalus sanguineus s.l., como vector alternativo de FMMR y de enfermedades rickettsiales en los perros, por su importancia en veterinaria (Santodomingo et al. 2019; Rivera-Páez et al. 2018) y, más recientemente, en zoonosis (Eremeeva et al. 2011).

Considerando las numerosas posibilidades existentes para la extracción de ADN a partir de garrapatas, la presente investigación comparó el rendimiento y la utilidad de tres protocolos de extracción de ADN, a partir de garrapatas, en la amplificación del gen mitocondrial $16 \mathrm{~S}$ ribosomal y la detección de algunos agentes patógenos.

\section{MATERIALES Y MÉTODOS}

Garrapatas. 30 garrapatas del complejo Rhipicephalus sanguineus s.l. fueron colectadas durante el ,2015 en viviendas infestadas de la zona urbana del municipio de Sincelejo, del departamento de Sucre. Las garrapatas fueron sacrificadas, mediante congelamiento a $-20^{\circ} \mathrm{C}$ y se utilizaron machos no alimentados, para garantizar que los posibles agentes, que puedan infectarlas, no provengan de la sangre ingerida. La identificación de las garrapatas, se realizó utilizando las claves de Barros-Battesti et al. (2006); además, estas poblaciones se han caracterizado previamente con el gen mt16S.

Cada garrapata, se cortó longitudinalmente, a través de las coxas y esta porción longitudinal fue dividida en 3 piezas de similar tamaño y, cada una, se utilizó en un método de extracción de ADN (Figura 1). La asignación de un fragmento de garrapata a un protocolo de extracción de ADN, se realizó al azar, con el fin de minimizar el sesgo y la influencia de la masa de cada fragmento cortado sobre el rendimiento del protocolo de extracción.

Extracción de ADN total a partir de garrapatas. Tres métodos de extracción de ADN fueron valorados: A) un método comercial, 


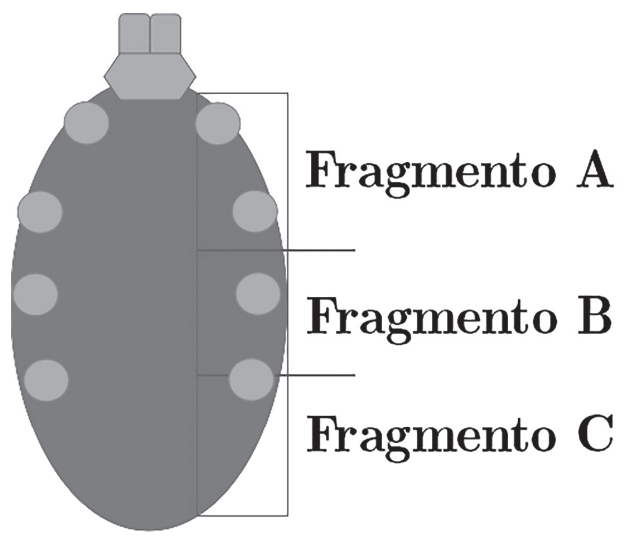

Figura 1. Diagrama de corte de una garrapata no ingurgitada, para la comparación entre métodos de extracción de ADN.

basado en Columna; B) un protocolo, fundamentado en el agente caotrópico Tiocianato de Guanidina, disponible comercialmente (Chomczynski, 1993) y C) el método universal, sustentado en alta concentración de sales (Aljanabi \& Martínez, 1997). A continuación, se describen brevemente cada una de las metodologías mencionadas.

Extracción ADN en Columnas (Columnas). En este ítem, se evaluó el Isolate II Genomic DNA Kit (Bioline, UK), siguiendo las instrucciones del fabricante. Brevemente, la muestra de tejido fue macerada manualmente, en un tubo de 1,5mL (Eppendorf ${ }^{\mathrm{TM}}$ ), al que se le adicionó $180 \mu \mathrm{L}$ de bufer de lisis GL, más $25 \mu \mathrm{L}$ de solución de Proteinasa $\mathrm{K}$ y se dejó incubar por 3 horas, a $56^{\circ} \mathrm{C}$. Posteriormente, se agregó $200 \mu \mathrm{L}$ de bufer de lisis G3 y se incubó a $70^{\circ} \mathrm{C}$, por 10 minutos; luego, se le adicionó $210 \mu \mathrm{L}$ de etanol. En seguida, la muestra se transfirió a un tubo de $2 \mathrm{~mL}$ (Eppendorf ${ }^{\mathrm{TM}}$ ), que contenía una columna y se centrifugó a $11.000 \mathrm{~g}$, por un 1 minuto; después, se realizaron dos lavados: en el primero, se adicionó $500 \mu \mathrm{L}$ de bufer GW1 y, en el segundo, se agregó $600 \mu \mathrm{L}$ de bufer GW2; para cada uno de ellos, se centrifugó a 11.000g, por 1 minuto, siempre descartando el líquido filtrado. Una centrifugación adicional fue realizada, para remover los residuos de etanol. Finalmente, se adicionó $50 \mu \mathrm{L}$ de bufer de elución y se incubó a temperatura ambiente por 1 minuto y se centrifugó a $11.000 \mathrm{~g}$, por 1 minuto; luego, se retiró la columna y el filtrado fue almacenado, a $-20^{\circ} \mathrm{C}$, hasta su uso.

Extracción ADN con Tiocianato de Guanidina (TRIzol). La muestra de tejido se homogenizó en $400 \mu \mathrm{L}$ de la preparación comercial de Tiocianato de Guanidina (TRIzol, Invitrogen), se maceró completamente y se incubó por 5 minutos; luego, se adicionó $100 \mu \mathrm{L}$ de Cloroformo y se agitó el tubo, hasta homogenizar completamente. Las muestras, se incubaron por 3 minutos, a temperatura ambiente y se centrifugaron a $12000 \mathrm{~g}$, por 15 minutos, a $4^{\circ} \mathrm{C}$. Para precipitar el ADN, se eliminó la fase acuosa, obtenida después de la centrifugación, se adicionó $200 \mu \mathrm{L}$ de Etanol absoluto, se mezcló y se dejó a temperatura ambiente por 3 minutos; posteriormente, se centrifugó a $2000 g$, por 5 minutos, a $4^{\circ} \mathrm{C}$. Se eliminó el sobrenadante y el pellet, se lavó con $400 \mu \mathrm{L}$ de Citrato de Sodio 0,1M en Etanol al 10\% y se agitó mediante un agitador electrónico, durante 30 minutos, a temperatura ambiente; en seguida, se centrifugó a $2000 \mathrm{~g}$, por 5 minutos, a $4^{\circ} \mathrm{C}$; este paso, se repitió dos veces. Acto seguido, se adicionó $600 \mu \mathrm{L}$ de etanol y se centrifugó a $2000 \mathrm{~g}$, por 5 minutos, a $4^{\circ} \mathrm{C}$; el sobrenadante fue eliminado y el pellet se dejó secar a temperatura ambiente; por último, se resuspendió en $50 \mu \mathrm{L}$ de agua ultrapura y almacenado a $-20^{\circ} \mathrm{C}$, hasta su uso. Estas modificaciones fueron realizadas en nuestro laboratorio, siguiendo los lineamientos del fabricante.

Extracción ADN con altas concentraciones de sales (Sales). La muestra de tejido se maceró en $400 \mu \mathrm{L}$ de bufer de lisis salino (0.4M NaCl, 10 mM Tris-HCl pH 8.0 y 2mM EDTA pH 8.0), con un micropistilo. Luego, se adicionó $40 \mu \mathrm{L}$ de SDS $20 \%$ y $8 \mu \mathrm{L}$ de proteinasa $\mathrm{K}$ y se mezcló; la mezcla, se incubó durante dos horas, a $65^{\circ} \mathrm{C}$, seguida por inactivación de la proteasa, a $94^{\circ} \mathrm{C}$, durante 5 minutos. A continuación, $300 \mu \mathrm{L}$ de $\mathrm{NaCl} 6 \mathrm{M}$ se adicionó a cada tubo (Eppendorf ${ }^{\mathrm{TM}}$ ), se agitó por vortex y se centrifugó, a $11.882 g$, por 30 minutos, a $4^{\circ} \mathrm{C}$. El sobrenadante obtenido fue transferido a un nuevo tubo, se le adicionó un volumen igual de isopropanol e incubó a $-20^{\circ} \mathrm{C}$, durante 1 hora. Posteriormente, las muestras se centrifugaron a $11.882 \mathrm{~g}$, por $20 \mathrm{~min}$, a $4^{\circ} \mathrm{C}$. El pellet resultante, se lavó dos veces con etanol al 70\%, secado a temperatura ambiente y se re-suspendió en $50 \mu \mathrm{L}$ de agua ultra pura y almacenado a $-20^{\circ} \mathrm{C}$, hasta su uso.

Evaluación de calidad y cantidad de ADN de garrapatas. El ADN extraído de las 30 muestras de $R$. sanguineus s.l (90 muestras), se les evaluó: I) valoración cuantitativa del material genético, en un espectrofotómetro NanoDrop 1000 (BioRad Laboratories, Hercules, USA), con el fin de determinar el rendimiento de cada protocolo y parámetros de pureza relativa (Relación 260/230, contaminación por proteínas y compuestos fenólicos y carbohidratos) y II) Una evaluación cualitativa de la calidad del $\mathrm{ADN}$, mediante amplificación de un fragmento de $\sim 360 \mathrm{pb}$ del gen mt16S, empleando los cebadores 16S+1 (5'-CCG GTC TGA ACT CAG ATC AAG T-3’) y 16S-2 (5'-T'TA CGC TGT TAT CCC TAG AG-3'), propuestos por Black \& Piesman (1994); el éxito de amplificación, se refiere a la existencia del ampliación esperado, sin tener en cuenta la intensidad del mismo. 
Todas las PCR fueron realizadas en un volumen de $25 \mathrm{uL}$ de reacción de PCR, empleando $1,5 \mathrm{mM} \mathrm{MgCl}$, $1.5 \mathrm{U}$ Biolase Taq DNA Polymerase (Bioline, UK) y $3 \mathrm{uL}$ de cada extracto de ADN. Los productos de PCR fueron visualizados en geles de agarosa 1.5\%, con adición previa de la tinción EZ-Vision (Amresco, Cleveland, USA), en un fotodocumentador Quantum ST4 (Vilber Lourmat, Marne-La-Válle, Francia).

Infección por Agentes Transmitidos por Garrapatas. Además de las evaluaciones cuantitativas y cualitativas de laboratorio antes mencionadas, también se realizaron ensayos de detección de agentes rickettsiales, de los géneros Rickettsia, Ehrlichia y Anaplasma y protistas del género Babesia.

En cada ensayo de PCR, se incluyó un control positivo y agua ultrapura, el control negativo; la composición de la mezcla de PCR fue similar a la descrita anteriormente, para el gen mt16S de garrapatas. Los genes para los ensayos de detección de rickettsiales y de piroplasmas, así como los cebadores empleados, controles positivos usados y referencias de las condiciones de amplificación, se encuentran en la tabla 1.

Análisis de Datos. La consistencia y la variabilidad del desempeño de cada protocolo de extracción de $\mathrm{ADN}$, se valoró mediante estimaciones del rendimiento (ng/uL): concentración media de $\mathrm{ADN}(\mu \mathrm{R})$, mediana (mdnR), valores Min (minR) y Max (maxR), la amplitud del rendimiento $(\Delta \mathrm{R}=\max \mathrm{R}-\mathrm{min} \mathrm{R})$ y el rango intercuartílico (RIQ 25\%-75\%). Además, se consideró la estimación de pureza por la Relación 260/230, relación que, a menudo, se puede ver afectada por la presencia de EDTA, compuestos fenólicos y polisacáridos. Las estimaciones de rendimiento y la pureza de ácidos nucleicos, se realizaron en un espectrofotómetro NanoDrop 1000 (ThermoFisher).

Las variables rendimiento y pureza fueron sometidas a prueba de normalidad de Shapiro-Wilk (SW), previo al análisis, para determinar su nivel de ajuste a distribución normal, debido a la naturaleza no paramétrica de ambas variables $\left(\mathrm{SW}_{\text {rendimiento }}=0.5088\right.$, $\mathrm{p}$-value $=$

Tabla 1. Genes, cebadores y controles empleados para los ensayos de detección de algunos patógenos transmitidos por garrapatas en las muestras analizadas.

\begin{tabular}{|l|c|c|l|c|}
\hline \multicolumn{1}{|c|}{ Agente } & Gen - Tamaño & Cebadores & Control + & Ref. \\
\hline Rickettsia & Citrato Sintasa (gltA) $-401 \mathrm{pb}$ & $\begin{array}{c}\text { CS-78 } \\
\text { CS-323 }\end{array}$ & R. rickettsii & $\begin{array}{c}\text { Campos-Calderón } \\
\text { et al. 2016 }\end{array}$ \\
\hline Anaplasmataceae & AND ribosomal 16S $(r r s)-345 \mathrm{pb}$ & $\begin{array}{c}\text { Ehr16SD } \\
\text { Ehr16SR }\end{array}$ & E. canis & $\begin{array}{c}\text { Campos-Calderón } \\
\text { et al. 2016 }\end{array}$ \\
\hline Babesia & ADN ribosomal $18 \mathrm{~S}-450 \mathrm{pb}$ & $\begin{array}{c}\text { PiroA1 } \\
\text { PiroB }\end{array}$ & B. bigemina & Jefferies et al. 2003 \\
\hline
\end{tabular}

$7.733 \times 10^{-16} ; \mathrm{SW}_{260 / 230}=0.93258, \mathrm{p}$-value $\left.=1.633 \times 10^{-4}\right)$; se empleó una prueba no paramétrica de Kruskal-Wallis y prueba de rangos de Dunn, con corrección de Holm, para determinar la existencia de diferencias estadísticas $\left(a_{\text {global }}=0.05\right)$, entre los protocolos de extracción.

Adicionalmente, la comparación de los éxitos de amplificación del gen mt16S de garrapatas entre protocolos de extracción de ADN, se realizó mediante Comparaciones Pareadas de Fisher $\left(\mathbf{a}_{\mathrm{global}}=0.05\right)$, con corrección de Holm (paquete fmsb), con el fin de determinar si alguno de los protocolos de extracción permitía un mayor éxito de amplificación del gen mitocondrial evaluado. En caso de no amplificación del fragmento mitocondrial esperado, los extractos de ADN fueron diluidos (1:2, 1:5 y 1:10) y sometidos nuevamente a PCR, con el fin de determinar si la negatividad inicial se debía a la presencia de inhibidores de PCR.

Finalmente, se realizó un análisis descriptivo de costo/beneficio para la extracción de ADN con los 3 métodos empleados, teniendo en consideración el rendimiento, la pureza y el éxito de amplificación de cada uno de ellos. Todos los procedimientos estadísticos mencionados fueron realizados en el programa R 3.2.3 (R Development Core Team).

\section{RESULTADOS Y DISCUSIÓN}

En términos generales, el método de extracción con Tiocianato de Guanidina (TRIzol) provee mayores concentraciones medias de material genético $(\mu=274,17 \mathrm{ng} / \mathrm{uL})$, seguido por el método de extracción con altas concentraciones salinas ( $\mu=8,83 \mathrm{ng} / \mathrm{uL})$ y finalmente el método de columnas ( $\mu=6,33 \mathrm{ng} / \mathrm{uL}$ ) (Tabla 2 ); sin embargo, el método basado en Columnas provee resultados más consistentes que el método de sales y de Tiocianato de Guanidina, si se considera la mediana y la amplitud del rendimiento, mostrando que el método de columnas tiene mejor estabilidad en su rendimiento (Figura 2).

La comparación del rendimiento y de pureza relativa entre los tres métodos de extracción indican la existencia de diferencias estadísticas significativas entre ellos $\left(H_{\text {Rendimiento }}=71,29\right.$, p-value $\chi^{2}=3,3 \times 10^{-16} ; \mathrm{H}_{260 / 230}=73,74, \mathrm{p}$-value $\left.=0\right)$; la prueba de rangos de 

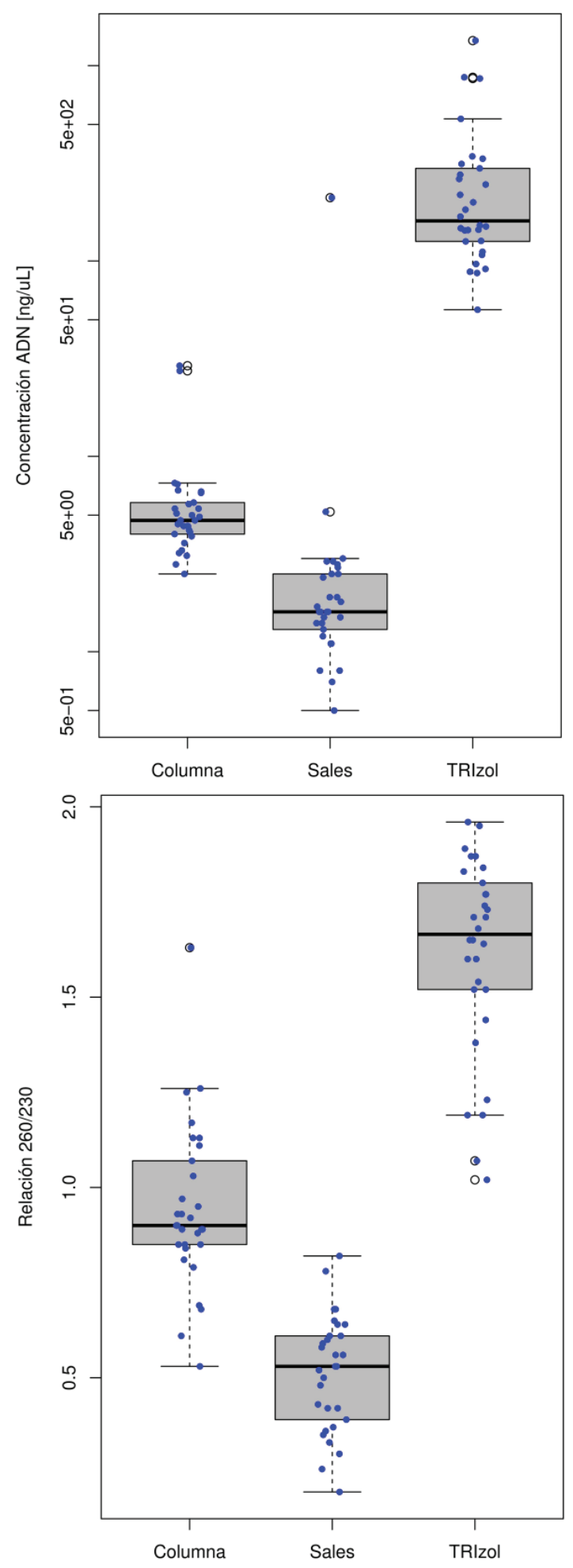

Figura 2. Rendimiento y pureza relativa (Relación 260/230) de los métodos de extracción de ADN total, a partir de garrapatas, de acuerdo con cada protocolo. Los puntos azules representan cada uno de los extractos de ADN, para cada protocolo. 
Tabla 2. Parámetros descriptivos de Rendimiento (ng/uL), de acuerdo con los métodos de extracción de ADN. $\mu$ : media, mdn: mediana, $\Delta$ : max-min, RIQ: rango intercuartílico, PD: Prueba de Dunn. Diferentes letras en la prueba de Dunn indican diferencias estadísticas entre los métodos de extracción.

\begin{tabular}{|l|l|c|c|c|c|c|c|c|}
\hline & & $\boldsymbol{\mu}$ & $\mathbf{m d n}$ & $\min$ & $\mathbf{m a x}$ & $\boldsymbol{\Delta}$ & RIQ & PD \\
\hline \multirow{4}{*}{ Rendimiento (ng/uL) } & TRIzol & 274,7 & 160,45 & 56,3 & 1343,4 & 1287,1 & $126,0-297,9$ & $\mathrm{~A}$ \\
\cline { 2 - 10 } & Sales & 8,83 & 1,6 & 0,5 & 210,9 & 210,4 & $1,30-2,50$ & $\mathrm{~B}$ \\
\cline { 2 - 10 } & Columna & 6,33 & 4,7 & 2,5 & 29,1 & 26,6 & $4,00-5,80$ & $\mathrm{C}$ \\
\hline & & $\boldsymbol{\mu}$ & $\mathbf{m d n}$ & $\min$ & $\mathbf{m a x}$ & $\boldsymbol{\Delta}$ & $\mathbf{R I Q}$ & PD \\
\hline \multirow{3}{*}{ Relación $\mathbf{2 6 0 / 2 3 0}$} & TRIzol & 1,61 & 1,66 & 1,02 & 1,96 & 0,94 & $1,52-1,77$ & $\mathrm{~A}$ \\
\cline { 2 - 10 } & Sales & 0,51 & 0,53 & 0,20 & 0,82 & 0,62 & $0,85-1,07$ & $\mathrm{~B}$ \\
\cline { 2 - 10 } & Columna & 0,94 & 0,90 & 0,53 & 1,63 & 1,1 & $0,39-0,61$ & $\mathrm{C}$ \\
\hline
\end{tabular}

Dunn muestra que los tres métodos evaluados son estadísticamente muy diferentes, a nivel de las dos variables analizadas, rendimiento y pureza relativa (Tabla 2, Figura 2). En este caso, se notó que el método basado en Tiocianato de Guanidina fue el mejor método en las dos variables (rendimiento y pureza del material genético), seguido por el método basado en columnas y, en último lugar, el método de altas concentraciones salinas.
Por otra parte, en la valoración cualitativa de los extractos de ADN, mediante la comparación del éxito de amplificación del gen mt16S, el método basado en Columnas permitió la amplificación en el total de muestras analizadas (30/30), seguido por el método basado en Tiocianato de Guanidina, con 93,33\% (TRIzol=28/30) y, finalmente, el método de sales, con 86,66\% (Sales=26/30) (Figura 3). La comparación de estas proporciones del éxito de amplificación
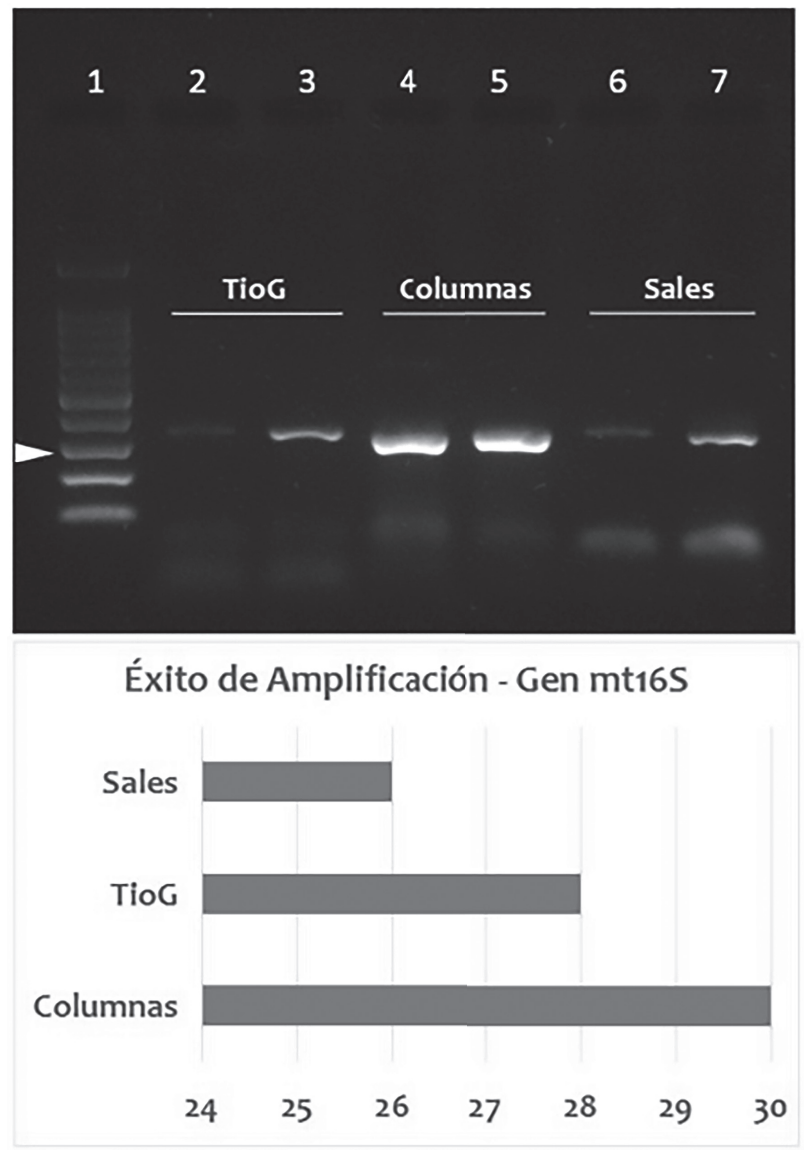

Figura 3. Amplificación del gen mitocondrial 16S de garrapatas (360pb) en el gel de agarosa, de acuerdo con cada método de extracción. La flecha blanca denota la banda de 300pb, en un marcador de peso molecular de 100pb. 
del gen mt16S no mostraron diferencias sustanciales entre los tres métodos de extracción de $\mathrm{ADN}\left(\chi^{2}=4,2857\right.$, d.f. $=2$, $\mathrm{p}$-value $\left.=0,1173\right)$.

A partir de los datos, se sugiere que la elección de uno u otro método de extracción afectan muy poco la calidad de ADN, con fines de utilización en pruebas de PCR; sin embargo, las bandas provenientes del método de columnas, casi siempre, se mostraron más intensas y definidas en comparación con los otros dos métodos (TRIzol y Sales), aunque esta diferencia no representó inconveniente en aplicaciones posteriores, como secuenciación de $\mathrm{ADN}$; la secuenciación de bandas, como las mostradas en la figura 3 , ha sido exitosa en nuestro laboratorio (resultados no mostrados).

Es evidente que el éxito de amplificación no se asocia de forma directa al rendimiento del método de extracción, de hecho, para la amplificación de 6 muestras de TRIzol fue necesaria la evaluación de diluciones (1:2 hasta 1:10) hasta la obtención de amplicones, ya que el éxito de amplificación inicial fue 73,3\% (22/30 extractos). En contraste, el éxito de amplificación alcanzado con los extractos de los métodos de columnas y altas concentraciones salinas fue logrado con un solo ensayo de PCR; por otro lado, el uso de diluciones de extractos de ADN obtenidos con el método de Sales no mejoró el éxito de amplificación en la PCR. La valoración estadística del éxito de amplificación realizada con el gen mt16S, se considera un procedimiento estándar y confiable en la evaluación de calidad de $\mathrm{ADN}$, previo a la búsqueda de agentes transmitidos por garrapatas (Takano et al. 2009).

La posible inhibición de la PCR en las muestras de ADN de los métodos Tiocianato de Guanidina y el método de sales, se debe, probablemente, a diferentes factores, entre los que se incluyen: la variabilidad del material genético extraído, además de la posible interacción con iones $\mathrm{Mg}^{2+}$, que impide la unión con cualquier ADN polimerasa, así como también, el uso de solventes químicos, como cloroformo, EDTA, etanol, dodecil sulfato de sodio (SDS) y cloruro de sodio (Peist et al. 2001).

Por otro lado, los 84 extractos de ADN positivos al gen mt16S ribosomal de garrapatas (30 de columnas, 28 de TRIzol y 26 de Sales) fueron negativos a la presencia de Rickettsia, Ehrlicbia/Anaplasma y Babesia; los controles positivos y negativos, se comportaron de la forma esperada. Esto muestra, que la predilección por un método de extracción de ADN (como Tiocianato de Guanidina), no supone una ventaja técnica en la detección de agentes transmitidos por garrapatas, siempre y cuando, el extracto haya sido previamente probado en la amplificación de un gen constitutivo en ensayos previos. A pesar de esto, los protocolos de extracción de ADN, basados en columnas, siguen siendo los más populares en la literatura

Tabla 3. Análisis de costo de reactivos para los protocolos de extracción de ADN usados, de acuerdo con cada protocolo. La equivalencia a USD es realizada considerando un valor de referencia de 3.000 pesos colombianos por dólar.

\begin{tabular}{|c|c|c|c|}
\hline Protocolo & Reactivo & Precio & Costo por Muestra \\
\hline \multirow{4}{*}{ Columna } & Isolate II Nucleic Acid Purification Kit & 2’200.000 & 10.000 \\
\hline & Etanol (Merck, Ref: 107017) & 285.000 & 15 \\
\hline & & Total Pesos & 10.015 \\
\hline & & Total USD & $\sim 3,33$ \\
\hline \multirow{7}{*}{ TRIzol } & TRIzol (Invitrogen,15596-018) & 1'800.000 & 3.600 \\
\hline & Cloroformo (Sigma, 25668-100ML) & 400.000 & 400 \\
\hline & Etanol (Merck, 107017, 4L) & 285.000 & 60 \\
\hline & Citrato Sodio (Sigma, US1667446-100MG) & 112.000 & 30 \\
\hline & Agua Ultrapura (Sigma, W4502-1L) & 250.000 & 13 \\
\hline & & Total Pesos & 4.103 \\
\hline & & Total USD & $\sim 1,367$ \\
\hline \multirow{9}{*}{ Sales } & Cloruro de Sodio (Sigma, 71376-1KG) & 400.000 & 80 \\
\hline & Trizma (Sigma, T6791-100G) & 250.000 & 1,2 \\
\hline & EDTA (Sigma, EDS-100MG) & 150.000 & 0,34 \\
\hline & Proteinasa K (Sigma, P2308-25MG) & 300.000 & 1.950 \\
\hline & Isopropanol (Sigma, I9516-500ML) & 350.000 & 350 \\
\hline & Etanol (Merck, Ref: 107017) & 285.000 & 30 \\
\hline & Agua Ultrapura (Sigma, W4502-1L) & 250.000 & 13 \\
\hline & & Total Pesos & $2.444,54$ \\
\hline & & Total USD & $\sim 0.814$ \\
\hline
\end{tabular}


científica de agentes transmitidos por garrapatas, probablemente, a la pureza del extracto y la baja contaminación (Ammazzalorso et al. 2015).

Otros métodos de extracción de ADN, a partir de garrapatas, como Fenol-Cloroformo (Halos et al. 2004), altas concentraciones salinas con Acetato de Potasio (Rodríguez et al. 2014), Hidróxido de Amonio (Morán-Cadenas et al. 2007) y diferentes métodos basados en columnas (Ammazzalorso et al. 2015), han sido comparados o utilizados en estudios de agentes asociados a garrapatas. En algunos de ellos, se reportan rendimientos de $10 \mathrm{ng} / \mathrm{uL}$, a partir de adultos que, eventualmente, se pueden mejorar, mediante maceración con cuadrisección de garrapatas o maceración con perlas (Ammazzalorso et al. 2015). En nuestro caso, los rendimientos de los métodos de sales y de columnas fueron muy similares a los reportados por Ammazzalorso et al. (2015), utilizando kits de extracción, aunque nuestro material para la extracción de ADN fue solo la tercera parte de un corte longitudinal de garrapata (Figura 2). La implementación de maceración del fragmento de la garrapata con perlas metálicas autoclavables de 4mm (BeadBug - BenchMark Scientific ó Tissue Lyser II - Qiagen) previo al protocolo de extracción de ADN con sales, facilita el escalado del proceso, manteniendo un bajo costo operacional.

De acuerdo con los costos, el método en columnas presenta un valor $\sim 3,33$ USD por muestra (costo real variable, debido al cambio de moneda en Latinoamérica), mientras que el método Tiocianato de Guanidina presenta un costo base de $\sim 1,3$ USD por muestra (si consideramos el uso de reactivos adicionales, como Cloroformo, Citrato de Sodio y Etanol). En contraste, el costo del protocolo de sales empleado es $\sim 0,81 \mathrm{USD}$ por muestra (Tabla 3 ).

En consideración de la relación costo/beneficio de cada uno de los protocolos de extracción de ADN y del éxito de amplificación obtenido con cada uno de ellos, el método de altas concentraciones salinas puede representar una buena alternativa a métodos comerciales estándar y ser implementado en cualquier laboratorio de investigación y, con ello, favorecer la masificación de investigaciones en sistemática molecular de vectores y agentes transmitidos por garrapatas.

La extracción de ADN de especies de garrapatas es de gran importancia para estudios genéticos, así como también, la detección de patógenos en estos vectores (Muñoz-Leal et al. 2019; Ringo et al. 2018). Según los métodos de extracción de ADN de garrapatas probados, el método comercial, basado en columnas, presentó altos rendimientos de ADN, probado junto a la amplificación del segmento del gen mt16S, al igual que el método Tiocianato de Guanidina. El método de altas concentraciones salinas, se recomienda por su calidad de ADN y bajo costo, lo que facilita la realización de extracción del material genético a gran escala.

Agradecimientos: Al grupo Investigaciones Biomédicas, por facilitar las instalaciones para el desarrollo de los experimentos. Conflicto de intereses: El manuscrito fue preparado y revisado con la participación de todos los autores, quienes declaramos que no existe ningún conflicto de intereses que ponga en riesgo la validez de los resultados presentados. Financiación: Este estudio fue financiado por la Convocatoria Nacional para Estudios de Doctorados Nacionales 528/2011.

\section{REFERENCIAS}

1. ALJANABI, S.; MARTINEZ, I. 1997. Universal and rapid salt-extraction of high quality genomic DNA for PCRbased techniques. Nucleic Acids Res. 25:4692-4693. https://doi.org/10.1093/nar/25.22.4692

2. AMMAZZALORSO, A.; ZOLNIK, C.; DANIELS, T.; KOLOKOTRONIS, S. 2015. To beat or not to beat a tick: Comparison of DNA extraction methods from ticks (Ixodes scapularis). Peer J. 13(3):e1147. https://doi.org/10.7717/ peerj. 1147

3. BARBIERI, A.; VENZAL, J.; MARCILI, A.; ALMEIDA, A.; GONZÁLEZ, E.; LABRUNA, M. 2013. Borrelia burgdorferi sensu lato infecting ticks of the Ixodes ricinus complex in Uruguay: first report for the Southern Hemisphere. Vector Borne Zoonotic Dis. 13:147-153. https://doi.org/10.1089/ vbz.2012.1102

4. BARROS-BATTESTI, D.M.; ARZUA, M.; BECHARA, G.H. 2006. Carrapatos De Importancia Médico-veterinaria Da Regiao Neotropical: Um Guia Ilustrado Para Identificação De Espécies. São Paulo: Vox/ International Consortium on Ticks and Tick-borne Diseases (ICTTD-3)/Butantan. 223p.

5. BLACK, W.; PIESMAN, J. 1994. Phylogeny of hard- and soft-tick taxa (Acari: Ixodida) based on mitochondrial 16S Rdna sequences. Proc Natl Acad Sci USA. 91:10034-10038. https://doi.org/10.1073/pnas.91.21.10034

6. BLACK, W.; KLOMPEN, J.; KEIRANS, J. 1997. Phylogenetic relationships among tick subfamilies (Ixodida: Ixodidae: Argasidae) based on the $18 \mathrm{~S}$ nuclear rDNA gene. Mol Phylogenet Evol. 7:129-144. https://doi.org/10.1006/ mpev.1996.0382

7. BOULANGER, N.; BOYER, P.; TALAGRAND-REBOUL, E.; HANSMANN, Y. 2019. Ticks and tick-borne diseases. Medecine et Maladies Infectieuses. Elsevier Masson SAS. 49(2):87-97. https://doi.org/10.1016/ j.medmal.2019.01.007

8. CABEZAS-CRUZ, A.; VAYSSIER-TAUSSAT, G.; GREUB, G. 2018. Tick-borne pathogen detection: what's new? Microbes Infect. 20(7-8):441-444.

9. CAMPOS-CALDERÓN, L.; ÁBREGO-SÁNCHEZ, L.; SOLÓRZANO-MORALES, A.; ALBERTI, A.; TORE, G.; ZOBBA, R.; JIMÉNEZ, A.; DOLZ, G. 2016. Molecular 
detection and identification of Rickettsiales pathogens in dog ticks from Costa Rica. Ticks Tick Borne Dis. 7(6):11981202. https://doi.org/10.1016/j.ttbdis.2016.07.015

10. CHOMCZYNSKI, P. 1993. A reagent for the single-step simultaneous isolation of RNA, DNA and proteins from cell and tissue samples. Biotechniques. 15:532-537. https:/ / doi.org/10.1038/news.2010.498

11. EREMEEVA, M.; ZAMBRANO, M.; ANAYA, L.; BEATI, L.; KARPATHY, S.; SANTOS-SILVA, M.; SALCEDA, B.; MACBETH, D.; OLGUIN, H.; DASCH, G.; ARANDA, C. 2011. Rickettsia rickettsia in Rhipicephalus ticks, Mexicali, Mexico. J. Med. Entomol. 48:418-421. https://doi. org/10.1603/ME10181

12. GUEDES, E.; LEITE, R.; PRATA, M.; PACHECO, R.; WALKER, D.; LABRUNA, M. 2005. Detection of Rickettsia ickettsia in the tick Amblyomma cajennense in a new Brazilian spotted fever-endemic area in the state of Minas Gerais. Mem Inst Oswaldo Cruz. 100:841-845. https:// doi.org/10.1590/S0074-02762005000800004

13. HALOS, L.; JAMAL, T.; VIAL, L.; MAILLARD, R.; SUAU, A.; LE MENACH, A.; BOULOUIS, H.; VAYSSIERTAUSSAT, M. 2004. Determination of an efficient and reliable method for DNA extraction from ticks. Vet. Res. 35:709-713. https://doi.org/10.1051/vetres:2004038

14. JEFFERIES, R.; RYAN, U.M; MUHLNICKEL, C.J.; IRWIN, P. 2003. Two Species of Canine Babesia in Australia: Detection and Characterization by PCR. Journal of Parasitology. 89(2):409-412. https://doi.org/10.1645/00223395(2003)089[0409:TSOCB] 2.0.CO;2

15. JONGEJAN, F.; UILENBERG, G. 2004. The global importance of ticks. Parasitology. 129(1):3-14. https:// doi.org/10.1017/S0031182004005967

16. MARRELLI, M.; SOUZA, L.; MARQUES, R.; LABRUNA, M.; MATIOLI, S.; TONON, A.; RIBOLLA, P.; MARINOT'TI, O.; SCHUMAKER, T. 2007. Taxonomic and phylogenetic relationships between neotropical species of ticks from genus Amblyomma (Acari: Ixodidae) inferred from second internal transcribed spacer sequences of rDNA. J. Med. Entomol. 44:222-228. https://doi.org/10.1093/ jmedent/44.2.222

17. MORÁN-CADENAS, F; SCHNEIDER, H.; LOMMANO, E.; BURRI, C.; MORET, J.; GERN, L. 2007. A comparison of two DNA extraction approaches in the detection of Borrelia burgdorferi sensu lato from live Ixodes ricinus ticks by PCR and reverse line blotting. Vector-Borne Zoonotic Dis. 7:555-561. https://doi.org/10.1089/vbz.2006.0596
18. MUÑOZ-LEAL, S.; LOPES, M.; MARCILI, A.; MARTINS, T.; GONZÁLEZ-ACUÑA, D.; LABRUNA, M. 2019. Anaplasmataceae, Borrelia and Hepatozoon agents in ticks (Acari: Argasidae, Ixodidae) from Chile. Acta Tropica. 192:91-103.

19. NAVA, S.; GUGLIELMONE, A.; MANGOLD, A. 2009. An overview of systematics and evolution of ticks. Front. Biosci. 14:2857-2877. https://doi.org/10.2735/3418

20. NAVA, S.; BARBIERI, A.; MAYA, L.; COLINA, R.; MANGOLD, A.; LABRUNA, M.; VENZAL, J. 2014. Borrelia infection in Ixodes pararicinus ticks (Acari: Ixodidae) from northwestern Argentina. Acta Trop. 139:1-4. https:// doi.org/10.1016/j.actatropica.2014.06.010

21. PAROLA, P.; RAOULT, D. 2001. Ticks and tickborne bacterial diseases in humans: an emerging infectious threat. Clin. Infect. Dis. 32:897-928. https://doi.org/10.1086/319347

22. PEIST, R.; HONSEL, D.; TWIELING, G.; LOFFERT, D. 2001. PCR inhibitors in plant DNA preparations. Qiagen news 3:7-9.

23. PICHON, B.; EGAN, D.; ROGERS, M.; GRAY, J. 2003. Detection and identification of pathogens and host DNA in unfed host-seeking Ixodes ricinus L. (Acari: Ixodidae). J. Med. Entomol. 40:723-731. https://doi.org/10.1603/00222585-40.5.723

24. PICHON, B.; ROGERS, M.; EGAN, D.; GRAY, J. 2005. Bloodmeal analysis for the identification of reservoir hosts of tick-borne pathogens in Ireland. Vector-Borne Zoonotic Dis. 5(2):172-180. https://doi.org/10.1089/vbz.2005.5.172

25. RINGO, A.; ADJOU MOUMOUNI, P.; LEE, S.; LIU, M.; KHAMIS, Y.; GAO, Y.; XUAN, X. 2018. Molecular detection and characterization of tick-borne protozoan and rickettsial pathogens isolated from cattle on Pemba Island, Tanzania. Ticks and Tick-Borne Diseases. 9(6):1437-1445. https://doi.org/10.1016/j.ttbdis.2018.06.014

26. RIVERA-PÁEZ, F.; MARTINS, T.; OSSA-LÓPEZ, P.; SAMPIERI, B.; CAMARGO-MATHIAS, M. 2018. Detection of Rickettsia spp. In ticks (Acari: Ixodidae) of domestic animals in Colombia. Ticks Tick Borne Dis. 9(4):819-823.

27. RIVERA-PÁEZ, F.; LABRUNA, M.; MARTINS, T.; PEREZ, J.; CASTAÑO-VILLA, G.; OSSA-LÓPEZ, P.; GIL, C.; RODRIGUES, B.; ARICAPA-GIRALDO, H.; CAMARGO-MATHIAS, I. 2017. Contributions to the knowledge of hard ticks (Acari: Ixodidae) in Colombia. Ticks Tick Borne Dis. 9(1):25-66. https://dx.doi. org/10.1016/j.ttbdis.2017.10.008 
28. RODRÍGUEZ, I.; FRAGA, J.; NODA, A.; MAYET, M.; DUARTE, Y.; ECHEVARRIA, E.; FERNÁNDEZ, C. 2014. An alternative and rapid method for the extraction of nucleic acids from ixodid ticks by potassium acetate procedure. Brazilian Arch. Biol. Technol. 57:542-547. http://dx.doi.org/10.1590/S1516-8913201402005

29. SANTODOMINGO, A.; SIERRA-OROZCO, K.; CORTESPERDOMO, A.; CASTRO, L. 2019. Molecular detection of Rickettsia spp., Anaplasma platys and Theileria equi in ticks collected from horses in Tayrona National Park, Colombia. Exp. Appl. Acarol. 77(3):411-423.
30. SONENSHINE, D.; LANE, R.; NICHOLSON, W. 2002. Chapter 24: Ticks (Ixodida). Medical and veterinary entomology. En: Mullen, G.; Durden, L. (eds). Medical and Veterinary Entomology. Elsevier Science (Amsterdam). p.517-558.

31. TAKANO, A.; GOKA, K.; UNE, Y.; FUJITA, H.; SHIINO, T.; WATANABE, H.; KAWABATA, H. 2009. Isolation and characterization of a novel Borrelia group of tick-borne borreliae from imported reptiles and their associated ticks. Environ Microbiol. 12:134-146. https://doi.org/10.1111/ j.1462-2920.2009.02054.x 